\title{
NARRATIVA CINEMATOGRÁFICA: FUNCIONES Y RECURSOS DE STEVEN SPIELBERG COMO DIRECTOR
}

David Caldevilla Domínguez: UCM, España

Davidcaldevilla@ccinf.ucm.es

\section{Resumen:}

Quizá uno de los ciudadanos individuales más influyentes de nuestra época, Steven Spielberg ha construido su reputación sobre lo que se entiende como una combinación -idiosincrasia del cine comercial americano- de buen hacer técnico con guiones y mensajes comerciales. Me propongo aquí crear una base para determinar cuáles son los recursos estilísticos del director, y cómo estos -en particular su uso de la suspensión de la incredulidad-interactúan con su público, determinando así la importancia de su aportación estilística a la narrativa cinematográfica.

\section{Palabras Clave:}

Spielberg - Cine - Narrativa - Todorov - Chatman

\section{CINEMA NARRATIVE: STEVEN SPIELBERG'S FUNCTIONS \& RESOURCES AS DIRECTOR}

\section{Abstract:}

Perhaps one of the most influential private citizens of our time, Steven Spielberg has built his reputation on what is understood as a combination - akin to American commercial cinema - of good technique with comercial scripts and messages. I propose here to create a basis for determining what the stylistic resources of the director are, and how these - in particular his use of disbelief's suspension - interact with their audience.

Keywords:

Spielberg - Cinema - Narrative - Todorov - Chatman

\section{INTRODUCCIÓN:}

Independientemente de la eterna dicotomía entre crítica y taquilla; del cisma aparentemente insalvable entre el cine popular y el cine de calidad, que puede extrapolarse directamente al mismo cisma existente en la literatura; existen contadas creaciones que al pasar el tiempo reconcilian a ambas partes en una crítica positiva. No es extraño que, para bromear sobre la incultura social, los traductores españoles de Matt Groening recurrieran a Spielberg (" ¡Steven Spielberg le da mil vueltas a Shakespeare!" dice Bart Simpson en el episodio de 1990 "Homer's Odyssey", aunque 
el propio Groening recurrió a la internacionalmente desconocida figura de Steven Bochco) porque estamos ante el responsable de dar forma a algunos de los iconos Pop más importantes de los siglos XX y XXI. Y lo ha hecho con obras que han reconciliado -con el tiempo en algunos casos- a la taquilla con la crítica. Es posible que, al apelar de forma casi abierta y específica a la suspensión de la credulidad haya conseguido ablandar a un sector de los expertos que es consciente de que esto puede ser una parte legítima de una construcción narrativa ficticia. Estos factores hacen a Spielberg y su estilema, un campo de estudio propio y digno, en la que entiendo como la noble gesta de cerrar la brecha entre el espectador entendido y el casual, y para la que Spielberg puede, perfectamente, haber puesto las bases sobre la que otros intentan desesperadamente construir: la suspensión de la incredulidad, el final feliz, y el humor espolvoreado en la trama.

\section{OBJETIVOS:}

El objetivo es la formación de una base teórica que permita delimitar cuáles son los recursos estilísticos propios del director estudiado, y cómo, por ejemplo, su empleo de la suspensión de la incredulidad entre otros recursos y características de estilema afectan a su leal audiencia, determinando de este modo el calibre y medida de la aportación spielbergiana a la narrativa cinematográfica moderna.

\section{METODOLOGÍA:}

Me propongo repasar primeramente las principales teorías narrativas aplicadas a la narrativa general y cinematográfica para, simultáneamente, estudiar como las teorías más antiguas encajan con el medio más moderno, y cómo el estilema de Spielberg interactúa con dichas teorías aplicadas a la práctica y con el público. De este modo determinaremos cual es el posicionamiento correcto del director dentro de la materia de la narrativa (general y cinematográfica).

\section{DISCUSIÓN}

Formalismo, estructuralismo, retórica, psicoanálisis y semiótica, son las más conocidas posturas que se han adoptado a la hora de abordar la narrativa en publicaciones científicas. En todos los casos, el objeto común reside en estudiar el fenómeno audiovisual y su participación en el edificio de la comunicación, a fin de conocer el total de sus contenidos y posibilidades.

Para empezar es preciso reseñar brevemente algunas características de cada uno de estos abordajes:

Del primer desarrollo esquemático que nos va a permitir analizar ampliamente el fenómeno en su encarnación audiovisual, destacamos algunas de sus bases para encaminarnos.

El discurso/expresión o significante tiene como materia los medios de comunicación: en el sentido de que pueden comunicar historias y se conforma como discurso narrativo: la estructura de transmisión narrativa de información, que se compone de los elementos comunes a las narraciones en cualquier medio dado (el cinematográfico y televisivo en el caso que nos ocupa). La historia/contenido o 
significado presenta como materialización, las representaciones de acciones y/o objetos en mundos/entornos tanto reales como imaginarios, que pueden emularse en un medio narrativo, cribados por los códigos sociales propios del autor y de su correspondiente público. La forma que adquiere este contenido la constituyen los ingredientes de la historia narrativa: los sucesos, existentes y las conexiones que presenten.

Los componentes del plano de la expresión, se refieren a significados o contenidos. La sustancia/esencia del contenido/significado la constituyen todos los pensamientos y emociones comunes al género humano. El contenido adopta la forma de la estructura abstracta de relaciones y enlaces que el medio de expresión que la vehicula, impone sobre la propia sustancia que subyace. La expresión dentro de la narración es un campo que se basa en la dicotomía de la "historia" o contenido de la expresión narrativa, y el "discurso" que es la forma que adopta la citada expresión. Dentro de "discurso" es preciso diferenciar entre el discurso propiamente dicho, como tal estructura de la transmisión en el medio audiovisual, y la sustancia del discurso, que constituye su manifestación material en palabras, imágenes, música, sonidos, dibujos, y cualquier otra forma de expresión física de ideas.

El contenido narrativo se compone de sustancia de los hechos y sustancia de los existentes o posibles existentes que pueden representarse/imitarse por parte del autor, perteneciendo a la categoría de las referencias reales. Solo hay tres significados: suceso, personaje y detalle escénico. Los significantes son los elementos dentro del enunciado narrativo de un medio cualquiera, que representan a uno de los citados significados: por ejemplo: actividades o acciones (cualesquiera) para suceso; personas o entidades personificadas para personaje; y lugares o sus reconstrucciones para el detalle escénico.

Tzuetan Todorov en su "Categorías del relato literario" 1, enuncia concisamente el punto de partida de la narrativa, similarmente a como hace Seymour Chatman en su también relevante "Historia y discurso: La estructura narrativa en la novela y en el cine" 2 cuyo contenido relevante para el caso se resumen en un análisis de los elementos que constituyen la historia y el discurso, marcando a éste como objeto de teoría literaria. Entendido no como singular pero si como principal, al menos formalmente.

Estos autores entienden que existe una dicotomía efectiva, al más puro estilo Saussuriano, que define la estructura básica de la narración:

- Historia o el "qué narrado". Evoca una realidad, acontecimientos pasados, personajes imitando la vida real ${ }^{3}$, es decir: la concatenación de sucesos o

\footnotetext{
1Tzuetan Todorov:" Categorías del relato literario", artículo recogido en Análisis estructural del relato. Editorial Tiempo Contemporáneo. Buenos Aires. 1974. Pág. 155-192.

2 Seymour Chatman: Historia y discurso: La estructura narrativa en la novela y en el cine. Editorial Taurus. Madrid 1990.

3 Francisco García García:" El guion en los medios audiovisuales" . Artículo recogido en el Diccionario de ciencias y técnicas de la comunicación. Ediciones Paulinas. Madrid. 1991.
} 
contenido más lo que los denominados existentes (los detalles del escenario, los personajes) ${ }^{9}$.

- Discurso o el" cómo" se narra, la manera en que el narrador implica al espectador en la historia: "la expresión y medios a través de los cuales se comunica el contenido" .

Todo ellos queda adecuadamente representado en el diagrama propuesto por Chatman y que sirve como funcional herramienta para la disección del fenómeno audiovisual.

Aristóteles, en su Poética, ya entendía una separación similar, al considerar la imitación de acciones en el mundo real o praxis como constitutiva de argumento o logos, del cual se extraían, seleccionaban y reordenaban las partes que constituían la trama o mythos.

También la retórica clásica presenta ambos elementos: en ella la historia deriva de la inventio, mientras que el discurso nace de la dispositio ${ }^{10}$.

Esta coincidencia aristotélica ha sido más ampliamente estudiada por Rosa Pinto Lobo en su Tesis Doctoral.

El formalismo ruso, representado principalmente por Vladimir Propp, presenta esta distinción, sirviéndose únicamente de dos términos precisos: la historia base o fábula (suma del total de los hechos que la narración va a tratar) y trama o historia tal y como es contada enlazando los sucesos ${ }^{4}$. Fábula es la serie de sucesos relacionados que nos son comunicados durante la obra y que queda constituido por aquello que sucede en la trama: Es el medio por el cual la audiencia se entera de lo que ha ocurrido.

Las clasificaciones hasta ahora expuestas parecen pecar de un carácter marcadamente literario de base: poniendo el foco exclusivamente sobre lo narrativo en formato impreso, aportando en el proceso, el germen de lo que será posteriormente el foco de lo narrativo audiovisual cinematográfico. Así, una frase extraída de la obra de S. Chatman ${ }^{9}$, fuente acrisoladora del saber en narrativa, adquiere validez por su relevancia para nuestro campo de interés y que adjunto a continuación a modo de resumen:

" La teoría narrativa no tiene intereses especiales de tipo crítico. Su objetivo es un armazón de posibilidades por medio del establecimiento de los elementos constitutivos básicos de la narrativa."

\footnotetext{
${ }^{4}$ Boris Tomashevsky: Teoría de la literatura: Poética. Leningrado. 1925. Citado por Chatman en su Op. Cit. pág. 20.
} 
Llegando al final de esta sucinta enumeración de teorías narrativas, faltan por citarse la escuela estructuralista francesa, representada arquetípicamente por Claude Bremond ${ }^{5}$ y la semiótica.

Este se fundamente en la afirmación de que las narraciones son, en realidad, estructuras independientes del medio en el que se reproduzcan. Es estructura porque, como ya se ha dicho, posee:

- Integridad

- Transformación

- Autorregulación

Sin estos atributos, la estructura pasaría a ser una simple agregación. La narración conforma un conjunto porque está constituido por sucesos y existentes que son individualmente distintos de aquello que constituyen: son individuales, diferentes y forman parte de una misma narración secuencial, pues todos se interrelacionan mutuamente, llegando al nivel causal de interrelación. Además poseen dicha interrelación responde a reglas que les confieren de por sí una estructura de la que carecerían si se dispusieran de otro modo.

Una vez tratado el "qué" o "historia" separan el "cómo" en dos partes constituyentes:

- Forma narrativa: Es la estructura de transmisión narrativa en sí misma.

- Manifestación de esta forma: Su presencia en un medio de sustanciación concreto, tal como el escrito, oral, cinematográfico, etc.

Queda así escrito que el estructuralismo completa (respecto a significados y a visión) al formalismo, sobre todo al soviético, demasiado atados a la literatura fantástica rusa, agregando el concepto "manifestación" que abre la puerta a pensar en términos de expresión cinematográfica, dejando de ser deudores directos del entorno literario impreso. Esta herencia será progresivamente actualizada por otros teóricos del fenómeno, embebidos ya en un marco definidamente cinematográfico, pero retiene su importancia como base del estudio de la narrativa.

Para dar cierre este tríptico teórico, es preciso tratar a los semióticos.

La semiótica predica una distinción simplificada de los conceptos de expresión y contenido. Esta no abarca todos los elementos de la situación comunicativa. Para definir su significado se sirve de otra característica que la atraviesa y que referencia a sustancia y forma

Los componentes del plano expresivo nos enseñan los significados o componentes en el área del contenido.

${ }^{5}$ Claude Bremond:" La lógica de los posibles narrativos", artículo recogido en Análisis estructural del relato. Editorial Tiempo Contemporáneo. Buenos Aires. 1974. Pág. 87-180. 
La forma del contenido es, en este caso, la propia estructura de cada lenguaje en el que el mensaje se expresa. Así, esta teoría toma una gran deuda con la lingüística: autores como Roland Barthes $^{6}$ han adaptado estos principios a la narrativa:

La historia es el contenido dentro de la expresión narrativa, mientras que la forma que adquiere dicha expresión es el discurso. Es preciso establecer una diferenciación entre el discurso y la manifestación sustancial de este: palabras, páginas, dibujos, etc., que constituyen la sustancia de esta expresión narrativa. El contenido narrativo incluye una sustancia y una forma. La sustancia de los sucesos y de los existentes la forman la totalidad del universo junto a todos los posibles objetos, acontecimientos y abstracciones susceptibles de ser imitados de cualquier manera concebible por parte de un autor.

Barthes matiza "es difícil concebir un sistema de imágenes y objetos cuyos significados puedan existir independientemente del lenguaje" 13.

" Por tanto, las narraciones serán, para él, lenguas transmitidas a

través de palabras de comunicación verbal concreta o de otro tipo". (S.

Chatman, 1990, Pág. 25)

La pregunta importante para los semióticos es ¿Qué significa la narración en sí misma?. Los significados son tres:

$$
\begin{array}{ll}
* & \text { - Suceso } \\
* & \text { - Personaje } \\
* & \text { - Detalle escénico }
\end{array}
$$

Los significantes son los elementos del enunciado que representan a los tres anteriores.

Una vez tratado este punto, señalemos los aspectos de la estructura narrativa a partir de las relaciones que pueden darse entre sus partes.

En aras de la síntesis, sacrifico conscientemente la inclusión de muchos e importantes datos ${ }^{7}$, para citar el esquema que S. Chatman ${ }^{8}$ emplea para relacionar todo lo ya visto con el hecho comunicativo: es un esquema que sirve de punto englobador de todas las teorías formuladas hasta el momento de su publicación.

\footnotetext{
${ }^{6}$ Roland Barthes: Elementos de semiología. Editorial Alberto Corazón. Madrid. 1971. Pág. 10 y ss.

7 Visiones tan importantes como las de Todorov en lo referente al Relato como historia, lógica de las acciones, modelo triádico, homológico, personajes y relaciones, etc. O las de Jacques Aumont en" Cine y Narración" artículo dentro de "Estética del cine" en el que desarrolla conceptos como diégesis, problemas de referentes, la propia narración etc. Las de Mieke Bal en su introducción a la narratología en su libro "Teoría de la narrativa". O la del propio Claude Bremond en su artículo" La lógica de los posibles narrativos" la teoría del ciclo narrativo, etc.. Y para concluir las desarrolladas por Jesús García Jiménez en su artículo" Narrativa Audiovisual" dentro del Diccionario de ciencias y técnicas de la comunicación. Ediciones Paulinas. Madrid. 1991.

8 Seymour Chatman: Historia y discurso: La estructura narrativa en la novela y en el cine. Editorial Taurus. Madrid 1990.
} 
La mejor praxis de este autor reside en seleccionar sus fuentes para amalgamarlas, sinopsando el hecho narrativo como fenómeno analizado desde varios puntos de vista, que le son propios y que establecen el camino que recorre el autor y que no será luego analizado:

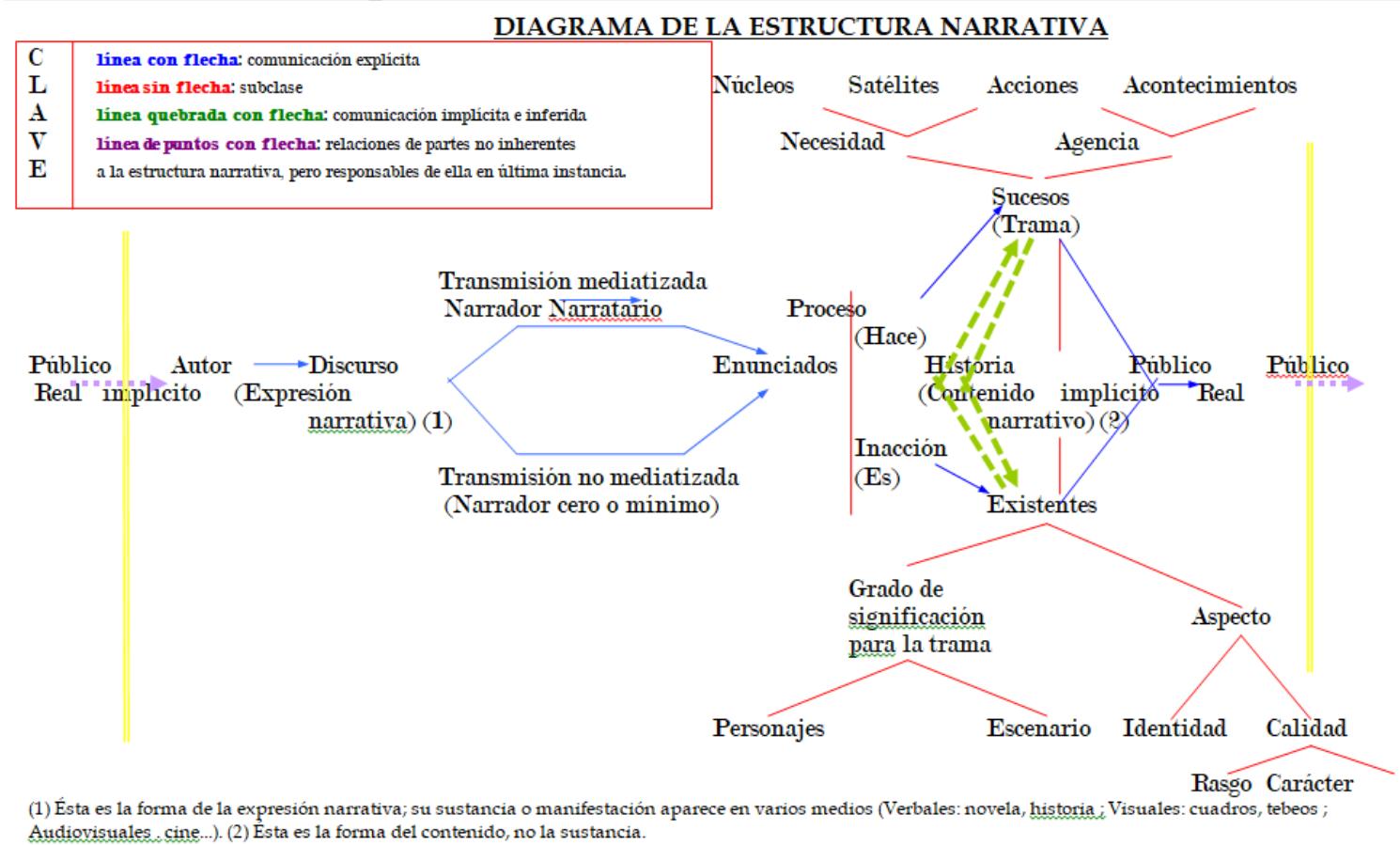

\subsection{Narrativa aplicada a los recursos}

Una vez analizado este esquema, tomamos a Graciela Reyes, en su "Polifonía textual: La citación en el relato literario"9 como guía introductora en los campos señeros de la narrativa que constituyen el punto de enfoque del prisma del autor, sus funciones y recursos, ingredientes el alma mater de la hipótesis:

" En el discurso literario hay un hablante o sujeto de enunciación primero, básico, el narrador autorizado, pero muchos enunciadores a los que se atribuyen discursos, y muchos locutores a los que momentánea, caprichosa o consistentemente se deja hablar alli donde la narración progresa como escena. Muchas son, pues, las voces de la narración asumidas o reproducidas por el narrador, y muchas las voces que el narrador cita, re-cita, sus-cita. En esta algarabía de discursos, por orígenes diferentes que constituyen la sustancia misma del relato, no siempre es fácil distinguir la voz fundadora, y en principio veraz, del narrador. Pero tal distinción es indispensable: si no sabemos quién lo dice, no sabemos si sucedió, o si es una alucinación, un sueño, un recuerdo, una fábula falsa en el marco de la fábula verdadera de la ficción.

\footnotetext{
${ }^{9}$ Graciela Reyes: Polifonía textual: La citación en el relato literario. Editorial Gredos. Madrid. 1984.
} 
El narrador, con sus afirmaciones descriptivas y narrativas, crea el sistema de proposiciones que constituyen el mundo < cierto > de la ficción, del cuento o de la novela. Su relato configura un interlocutor, el narratario que ha de tomar al pie de la letra las afirmaciones del narrador. El lector de carne y hueso que pone en el lugar del narratario, no lee la literatura como literatura; esa participación creativa comienza con la suspensión de incredulidad de la que ya nos habló Coleridge." 10 (G. Reyes, 1984, Pág. 67)

Esta suspensión de la incredulidad ha servido no sólo de elemento de estudio para analistas literarios, también es objeto de una mención explícita en los diálogos de la película" Instinto Básico" 11 (1992) de Paul Verhoeven, cuya protagonista femenina (Sharon Stone), una universitaria con licenciaturas en literatura y psicología, aplica sus conocimientos a su faceta como escritora de superventas, y basa el éxito de su trabajo en la correcta aplicación de la suspensión de la incredulidad en las mentes de sus lectores, a los que atrapa como una araña a las moscas.

En este punto surge el concepto informativo de "competencia y plenitud" además del de veracidad. Esta aclaración es necesaria por la idea de reconstrucción, dentro de la mente del miembro de la audiencia, de un mundo "emitido" por el autor o narrador cuyo acto comunicativo puede presentar defectos, pues si se trata de un narrador-personaje adecuadamente caracterizado, esos defectos son atribuibles directamente a él (ej. "El asesinato de Roger Ackroyd" de Agatha Christie) en el caso de un narrador en tercera persona, la situación se complica: con un narrador común, respondiendo a la conducta comunicativa extraña normal al acto concreto de emisión informativa, privado de los datos derivados de una transmisión puramente informativa; $y$ otro narrador impersonal y omnisciente que nos oculta deliberadamente qué tipo de narrador es aquel que despliega una fiabilidad menguada respecto al proceso descodificador del lector-receptor ${ }^{12}$, pero sin por eso ser un narrador liberado del compromiso de veracidad de sus narraciones.

Spielberg, en sus películas, se inclina por este papel de narrador impersonal omnisciente, sin interesarse por ningún otro tipo de narrador. La voz en off (recurso de atención en el que narrador y protagonista son el mismo) la vemos dentro de su filmografía sólo en" El color púrpura" y solo como solución narrativa para la lectura

\footnotetext{
10 Peter Ravinowitz, estudioso de muy marcado cariz semiótico, distingue cuatro tipos básicos de auditorio: 1) Audiencia actual. 2) Audiencia autorial (el auditorio que toma el texto como una comunicación ficticia producida por el autor). 3) Audiencia Narrativa (toma el texto como una comunicación auténtica del narrador). 4) Audiencia Ideal Narrativa (Interpreta la comunicación del narrador según los deseos de éste). Estas distinciones intentan dar cuenta del fenómeno de la lectura, donde los papeles señalados se cumplen simultáneamente. Estos conceptos están desarrollados por el propio Peter Ravinowitz en su obra Verdad en la ficción: Una reexamen de audiencias. Editorial Critical Inquiry. 1977.

11 "Instinto Básico " (1992) de Paul Verhoeven.

12 Por ejemplo, el narrador recurrente en la obra cinematográfica de Luis García Berlanga. Así, en su" Bienvenido, Míster Marshall " (1952) o" Calabuch" (1956), la voz en off del narrador con que se inician da un aire de etereidad heredada en parte del neorrealismo italiano. Esta conciencia supraterrena se plasma visualmente en" Bienvenido, Míster Marshall" mediante profundos contrapicados y en juegos de apariciones y desapariciones físicas de los intervinientes en la escena.
} 
de cartas por parte de la protagonista y en" La lista de Schindler" como la voz del mismo Oskar Schindler, que es quien lee las cartas que ha enviado a los líderes de la Alemania Nazi para obtener los contratos de suministro al ejército. La cámara subjetiva (otro recurso de atención de la narración, que hace coincidir la vista del espectador con la de un personaje, haciendo que la información que sale del guion coincida con lo que él observa subjetivamente) tampoco un recurso típico ni habitual de Spielberg, y cuando lo utiliza, tiene un carácter humorístico o puramente funcional sin significancia relevante (el oficial del submarino japonés mirando Los Ángeles mediante el periscopio en" 1941", el soldado alemán en el tanque mirando a través de los prismáticos, Indiana mirando a través de los prismáticos al tanque en" Indiana Jones y la última cruzada", o los guardacostas mirando a través de sus prismáticos en" Tiburón" etc.) No son recursos a los que Spielberg dote de una carga de significado plena, sino simplemente funcional y traído a colación por la propia historia, que demanda estos recursos.

Aunque al narrador literario y audiovisual le está permitido el ejercicio de ciertas licencias en aras de la historia, gracias a las que podemos examinar, los entresijos de los actos comunicativos naturales ${ }^{16} \mathrm{y}$ la manera en que transmiten las vivencias. Al narrador literario y audiovisual, paradójicamente, le está desacotada la avenida de la insinceridad.

Mieke Ball $^{13}$ y su esquema sobre el valor de la verdad, nos aclara el enfoque final sobre las posibilidades existentes:

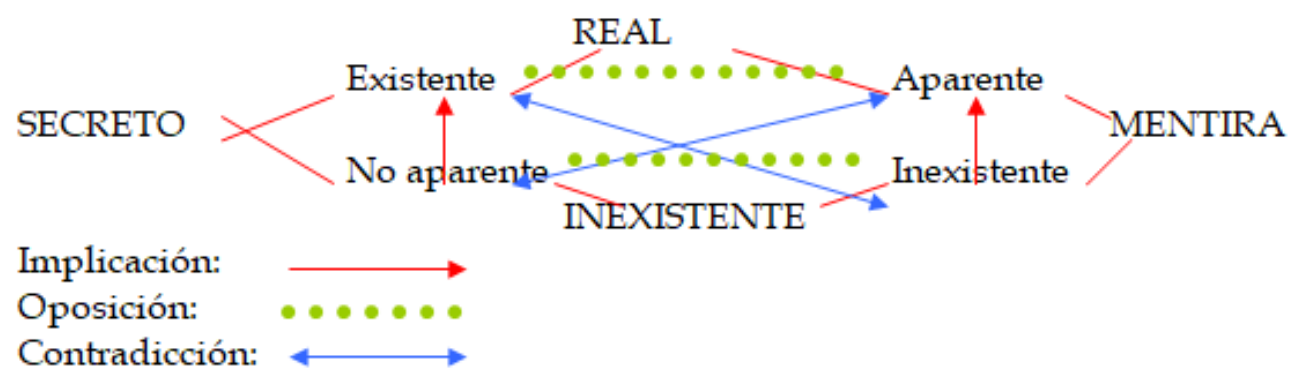

Los ejemplos cinematográficos son escasos pero relevantes. Por ejemplo, Alfred Hitchcock ${ }^{14}$ en" Pánico en la escena" (1950) ${ }^{15}$, plantea falsa "vuelta-atrás" en los

\footnotetext{
${ }^{13}$ Mieke Bal: Teoría de la narrativa: Una introducción a la narratología. Editorial Cátedra. Madrid.1990. Pág.43.

14 Alfred Hitchcock, (Londres, 1899 - Los Ángeles, 1980). Comenzó su periplo como director en la U.F.A. alemana en los 20. Volvió a Londres y allí en los 30 se hizo famoso. En 1940 llamado por David O. Selznick va a E.E.U.U., donde se especializa en películas de suspense e intriga detectivesca y de espionaje. Desde que los críticos franceses (François Truffaut sobre todo) de los años 50, a partir de "Cahiers du cinéma", reivindicaran su figura, ha sido tomado merecidamente como maestro del cine mundial.
} 
recuerdos de la protagonista. La acogida entre el público le desaconsejaron volver a engañar (o adornar los hechos), llevando a una definición del narrador de "sumo pontífice" garante de la veracidad de sus propias palabras, no relacionada con la capacidad de cumplimiento de los hechos en la realidad.

Otro ejemplo, sin consistir en una mentira en sentido estricto, lo tenemos en la oscarizada "El Golpe" 16 (1976) de George Roy Hill, que basa su sorpresa final en el encubrimiento de una parte importante y crucial de la información en manos del director-narrador de la película, transmitiéndonos de forma veraz y nada ominosa toda la información pero sólo hasta el momento final - incluido un "doble personaje": el guardaespaldas que protege a uno de los protagonistas y al que tomamos erróneamente por el asesino (Salino) y la camarera amable que resulta ser el realmente ese asesino (Loretta Salino) que trata de matar al protagonista Jhonny Cooper $^{17}$-, por lo que su estrategia de engañar al público gana en sutilidad: tras ganar nuestra confianza al desvelar quien es quien, no sospechamos ya que nos puedan ocultar información aún más relevante: la verdadera identidad de los agentes del Federales que solucionan sorpresivamente la trama, cambiando la forma del desenlace final, cuando todos creíamos que los timadores habían sido cazados, cerrando el final feliz del espectador.

David Mamet en su "Casa de juegos"18 (1987), quiso imitar el tono de engaño al espectador de "El Golpe" aunque sin llegar al nivel de ésta.

"El Golpe", sufrió las penalidades que acarrean las segundas partes, diez años después, a manos de Jeremy Paul Kagan, con resultados previsiblemente poco cumplidores. "El Golpe II" (1983). Fue importante en la carrera de Spielberg, quien decidió hacer la segunda parte de "Parque Jurásico" al ver lo que sucedió con esta película y con una criatura suya: "Tiburón".

Quizá sea W. Booth ${ }^{19}$ el autor que más ha profundizado en el concepto y grado de fiabilidad del narrador, creando en el proceso del concepto de "Narrador poco fiable" que no definiremos inmediatamente en beneficio del narrador como

15 "Pánico en la escena" (1950) cuenta la historia de un asesinato entre bastidores de un teatro, creando suspense en torno a las pesquisas de la policía para atrapar al asesino.

16 "El Golpe" (1973) de George Roy Hill. Es una de las obras maestras del cine de todos los tiempos. El argumento de la misma versa sobre un gran timo < de ahí el título > (500.000 \$ de los años 30) cuya víctima es un gángster de apuestas ilegales en Chicago que alardea de buena posición e intachable honra. Es una especie de "Regador regado" ("L' arroseur arrosé") de Louis Lumière en 1.895.

17 Con lo que ya no espera el espectador ninguna sorpresa más, al haber sido "tocado" levemente por esa acción y reconocer la habilidad para despistarnos del director. Incluso el jefe mafioso alude a él afirmando "Salino es nuestro mejor hombre".

18 "Casa de juegos" de David Mamet (1987). Remedo de" El Golpe". El argumento trata de una mujer timada que pretende devolver el favor a sus timadores aliándose con ellos. Acaba matando a uno de los estafadores al ser descubierta por éste.

${ }^{19}$ Wayne Booth: The rhetoric of fiction. Editorial University of Chicago Press. 1983. Define al "Narrador poco fiable" como el narrador falible, no equivalente al autor implícito (que es el que sustenta las normas y valores de la obra). 
garante de un mundo cierto dentro de esa ficción consensuada con el espectadorlector-receptor. Este narrador crea un sistema de proposiciones con sus descripciones y narraciones que sirven para delimitar la verdad, las mentiras, y en general lo que existe y lo que no (lo no mostrado: la información que no ha sido proporcionada y que nunca lo será pues no tiene carta de naturaleza para el universo o película narrados). De ahí el juego en el límite de la aceptabilidad de "El Golpe". Su relato se estructura en torno a un interlocutor (el narratario) que debe aceptar al pie de la letra los enunciados del narrador. El espectador-lector-receptor que empatiza con el narratario no afronta el texto como tal literatura: no asume la "suspensión de incredulidad".

Un grupo de lingüistas ha sacudido la teoría literaria calificando a la venerable figura del narrador como superflua en relato: El relato literario, dicen, carece de narrador ${ }^{20}$. Conclusión que transcribo por su importancia, pero sin compartirla, a fin de no incurrir en parcialidad a la hora de afrontar mi hipótesis, pues sería deshonesto plantear la existencia de un cierto elemento sin citar a los estudiosos del tema que contradicen la opción que se pretende defender.

Tal afirmación la fundamentan sobre una crítica a la consideración convencional del papel comunicacional de la lengua. Tal como ellos lo plantean, el relato literario existe por sí mismo. La idea de que el lenguaje no tiene por que cumplir solo o siempre funciones comunicativas, se apoya en las teorías de Banfield, que consideraba que, al necesitar las funciones comunicativas de la existencia de un "yo" hablante y un "tu" oyente, el lenguaje sirve además a funciones puramente expresivas. Es decir: funciones que no asumen un" tú" oyente. Funciones en las que el" yo" no implica el" tú " (monólogo interno, voz de la conciencia etc., por citar ejemplos). Esta propuesta, estructurada en voz pasiva arroja otra aserción categórica: que el "tú" siempre supone un "yo". Esta situación de asimetría sólo es verificable, según Banfeld, en textos de ficción. Estos textos sin narrador, no tienen entidad comunicativa, no como la narración literaria en tercera persona, que ni es comunicativa ni es expresiva; y el estilo libre indirecto, que es eminentemente expresivo.

Para cerrar la discusión en el terreno de lo lingüístico, tengamos en cuenta que hay dos cuestiones, como apunta Graciela Reyes: por un lado, la validez de una competencia lingüístico-literaria mediante la que solo un lector entrenado distingue las categorías gramatical y agramatical. Y por otro lado la validez de trabajar con oraciones (secuencias cuyo vínculo cohesionador está en la extensión gramatical), desatendiendo -en la teoría, que no en la práctica- el contexto ${ }^{21}$.

Como es fácil notar, al trasladar estas ideas al entorno audiovisual, es preciso recordar y revisitar los estudios de la corriente semiótica.

\footnotetext{
${ }^{20}$ Ann Banfield: Frases no narrables: Narración y representación en el lenguaje del relato literario. Boston y Londres. Editorial Routledge y Kegan Paul. 1982.

${ }^{21}$ Estos y otros problemas se discuten en la reseña de Brian Mc Hale en su Unspeakable sentences, unnatural acts, linguistics and poetics revisited. Editorial Poetics Today, IV, 1, 1983. Pág. 17-45.
} 
Desde este axioma del" tú" personaje cuyo rol asumimos ante la historia narrada por un emisor, aprendemos socialmente a representar ese papel para poder escuchar relatos que fingimos creer e incluso, tal como afirma Graciela Reyes ${ }^{22}$, aparentamos no conocer el desenlace y aparentamos sufrir o emocionarnos si así lo exige la narración (suspensión de la incredulidad). Sobre esta base psicológica sobre la que se fundamentan los grandes relatos de aventura, como la Trilogía de Indiana Jones. Spielberg demuestra como su gran facultad y habilidad el ser capaz de ubicarnos en la situación de ese "tú" receptor con mentalidad receptiva y con capacidad de asombro, aún a sabiendas de que los buenos ganarán, que al protagonista nunca le sobrevendrá ninguna desgracia irreversible y que todo es, en definitiva, una ficción rodada para nuestro disfrute. Pare ello se vale consistentemente de los mismos trucos y medios. Situaciones, personajes y otros ingredientes indispensables del relato que producen los efectos deseados de espectacularidad (el papel recurrente de los nazis como antagonistas) y la complicidad de la audiencia, indispensable para el final feliz. Incluso llega a la" resurrección" de personajes en su "En busca del Arca perdida" para que la experiencia del espectador sea agradable, omitiendo hechos como el intercambio del cesto que contiene a la heroína antes de subirlo al camión de explosivos, o que Indy ha sido capaz de saltar del tanque (La última cruzada) antes de que se despeñe por el acantilado.

\section{CONCLUSIONES:}

La importancia de Spielberg equivale a la que ostenta en el siguiente esquema:

Si la narración la constituye el polifónico discurso del narrador, junto al de igualmente polifónico de los personajes que este cita, la situación del autor/director queda extraída de la comunicación ficticia. Pero lejos de ser una estructura externa o ausente, es el director/autor el que emplea el discurso y lo cita. Ello sustenta la idea del sello autorial del director, porque el autor es aquel que focaliza aquello que se narra.

Siguiendo este tren de pensamiento, daremos por necesidad con estructuras narrativas que desvíen las posturas a entornos opcionales dentro del espectro creativo. Al ser personales, el autor se manifiesta como ente inventivo indiscutible. La inventio y la intellegentia de la misma mano que las alimenta.

\section{Bibliografía:}

Ann Banfield (1982) Frases no narrables: Narración y representación en el lenguaje del relato literario. Boston y Londres. Editorial Routledge y Kegan Paul.

Boris Tomashevsky (1925) Teoría de la literatura: Poética. Leningrado. Universidad de Leningrado

Brian Mc Hale (1983) Unspeakable sentences, unnatural acts, linguistics and poetics revisited. Editorial Poetics Today, IV, 1.

\footnotetext{
${ }^{22}$ Graciela Reyes: Polifonía textual: La citación en el relato literario. Editorial Gredos. Madrid.1984.
} 
Claude Bremond (1974) "La lógica de los posibles narrativos", artículo recogido en Análisis estructural del relato. Buenos Aires. Editorial Tiempo Contemporáneo.

Francisco García García (1991) "El guion en los medios audiovisuales" . Artículo recogido en el Diccionario de ciencias y técnicas de la comunicación. Madrid. Ediciones Paulinas.

Graciela Reyes (1984) Polifonía textual: La citación en el relato literario. Madrid. Editorial Gredos.

Graciela Reyes (1984) Polifonía textual: La citación en el relato literario. Madrid. Editorial Gredos.

Mieke Bal (1990) Teoría de la narrativa: Una introducción a la narratología. Madrid. Editorial Cátedra.

Peter Ravinowitz (1977) Verdad en la ficción: Una reexamen de audiencias. Chicago. Editorial Critical Inquiry.

Roland Barthes (1971) Elementos de semiología. Madrid. Editorial Alberto Corazón.

Seymour Chatman (1990) Historia y discurso: La estructura narrativa en la novela y en el cine. Madrid. Editorial Taurus.

Tzuetan Todorov (1974) "Categorías del relato literario", artículo recogido en Análisis estructural del relato. Buenos Aires. Editorial Tiempo Contemporáneo. 